\title{
Effects of uncertain warning signals on reaction time'
}

\author{
R. S. NICKERSON, ${ }^{2}$ A. M. COLLINS, AND J. MARKOWITZ \\ BOLT BERANEK AND NEWMAN, INC.
}

Three experiments were conducted in an attempt to assess the effectiveness of a warning signal in reducing reaction time when (1) the signal to respond (danger signal) follows the warning signal with a probability less than 1.0, and (2) the interval between warning and danger signals ( $W$ - $D$ interval) is variable. The required response was the depression of a foot pedal, as in automobile braking. It was determined that probabilistic warning information could be effective if observers made use of the $W$ - $D$ interval to prepare to make the response required by the danger signal. It was noted, however, that observers differed considerably in their tendency to do this. A model was proposed for describing different response strategies.

Advances in machine performance are almost always accompanied by increased demands on the human controller. Consider, for example, the latest generation of highperformance aircraft, or today's automobile in dense, high-speed traffic. When demands upon the operator become critical, a factor of prime importance is the speed with which an appropriate response can be made. We know that the speed with which a man can react to a stimulus depends, in part, upon the degree to which he expects it. In the laboratory we often try to ensure that an observer is prepared for a stimulus by preceding it with a "warning signal." In the field this is not commonly done.

In certain practical situations, a warning signal can be arranged to precede the danger signal. In the automotive context, for example, it has been proposed that a warning signal actuated, say, by decreased accelerator-pedal pressure, presage the occurrence of the brake light (Moore \& Smith,
1966; Crosley \& Allen, 1966; Rockwell \& Treiterer, 1966). Yet, because of the inherent uncertainty in practical situations, the warning signal can neither be a completely accurate predictor, nor can it precede the danger signal by a precisely defined time interval. These two parameters-the probability that a warning signal is followed by the danger signal, and the interval between the warning signal and the danger signal-were investigated in a series of three experiments which are described below.

\section{METHOD}

In all cases the Os were comfortably seated about $18 \mathrm{ft}$ from a display consisting of two lights mounted at eye level about 4 in. apart. The left light (warning light) appeared yellow, and the right light (danger signal) appeared red. The background was dimly lit, and the two lights were highly visible and easily discriminable. The rise time of the lights was approximately $40 \mathrm{msec}$. A PDP- 8 computer was used to control the experiments.

The response of interest was depression of a foot pedal. The O's task was to press the pedal as soon as, but not before, the danger (red) light came on. If the $O$ so chose, he could ignore the warning (yellow) light, but he could hardly avoid seeing it because of its proximity to the danger light.

The dependent variable of primary interest was the reaction time (RT) measured from the onset of the danger light to the actuation of the pedal. The independent variables manipulated were: (1) the probability of occurrence of the warning light, of the danger light, and of both; (2) the time between the onsets of the warning and danger lights, when, in fact, both occurred; (3) whether the warning light overlapped the danger light in

Table 1

Summary of Conditions in Three Experiments on Response Time to Signaled and Unsignaled Danger Events*

\begin{tabular}{|c|c|c|c|c|c|c|c|c|c|c|c|c|c|c|}
\hline $\begin{array}{c}\text { Experiment } \\
\text { No. } \\
\end{array}$ & Condition & $\begin{array}{c}\text { Non- } \\
\text { Overlapping } \\
\end{array}$ & Overlapping & \multicolumn{5}{|c|}{$\begin{array}{c}\text { Probability } \\
\text { (Trial Contained Warning Light) }\end{array}$} & \multicolumn{5}{|c|}{$\begin{array}{l}\text { Probability } \\
\text { (Trial Contained Danger Light) }\end{array}$} & $\begin{array}{l}\text { Secondary } \\
\text { Pedal Used }\end{array}$ \\
\hline \multirow[t]{2}{*}{1} & $\begin{array}{l}\mathrm{a} \\
\mathrm{b} \\
\mathrm{c} \\
\end{array}$ & & & $\begin{array}{l}\gamma \\
\gamma \\
\gamma\end{array}$ & & & & & & $\overline{\bar{\gamma}}$ & $\gamma$ & $r$ & & \\
\hline & $\begin{array}{l}\mathrm{d} \\
\mathrm{e} \\
\mathrm{f}\end{array}$ & $\begin{array}{l}\checkmark \\
\gamma \\
\gamma \\
\end{array}$ & & & & & & $\begin{array}{l}r \\
\gamma \\
\gamma \\
\end{array}$ & & $\checkmark$ & $\checkmark$ & 1 & & \\
\hline \multirow[t]{3}{*}{2} & $\begin{array}{l}a \\
b\end{array}$ & & & $\begin{array}{r}r \\
r\end{array}$ & & & & & & $\checkmark$ & & 1 & & $\begin{array}{r}r \\
r\end{array}$ \\
\hline & $\begin{array}{l}c \\
d\end{array}$ & 1 & & & & & & $r$ & & $r$ & & $\gamma$ & & $\begin{array}{l}\checkmark \\
\checkmark\end{array}$ \\
\hline & $\begin{array}{l}\mathrm{e} \\
\mathrm{f} \\
\end{array}$ & & $\checkmark$ & & & & & $\begin{array}{l}1 \\
1 \\
\end{array}$ & & $\gamma$ & & 1 & & $\begin{array}{r}r \\
\gamma \\
\end{array}$ \\
\hline \multirow[t]{3}{*}{3} & a & & & $\checkmark$ & & & & & & & & & $\gamma$ & $\gamma$ \\
\hline & $\begin{array}{l}b \\
c \\
d\end{array}$ & $\begin{array}{l}r \\
r \\
r\end{array}$ & & & $r$ & $r$ & $\checkmark$ & & & & & & $\begin{array}{l}1 \\
\text { d } \\
\text { d }\end{array}$ & $\begin{array}{l}\gamma \\
\gamma \\
\gamma\end{array}$ \\
\hline & $\begin{array}{l}\mathrm{e} \\
\mathrm{g} \\
\mathrm{g}\end{array}$ & & $\begin{array}{l}r \\
\gamma \\
\gamma\end{array}$ & & $\checkmark$ & 1 & $r$ & & & & 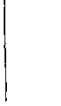 & & $\begin{array}{l}\gamma \\
\gamma \\
\gamma\end{array}$ & $\begin{array}{l}d \\
\gamma \\
\gamma\end{array}$ \\
\hline
\end{tabular}

*light warning light durations $(0.0,0.125,0.25,0.5,1.0,2.0,4.0$, and $8.0 \mathrm{sec})$ were used equiprobably. Note then that in Condition $1 d, e, f$ and $2 \mathrm{c}, \mathrm{d}$, although the warning light appeared with probability $=1$, it was of 0 duration $1 / 8$ of the cases. 


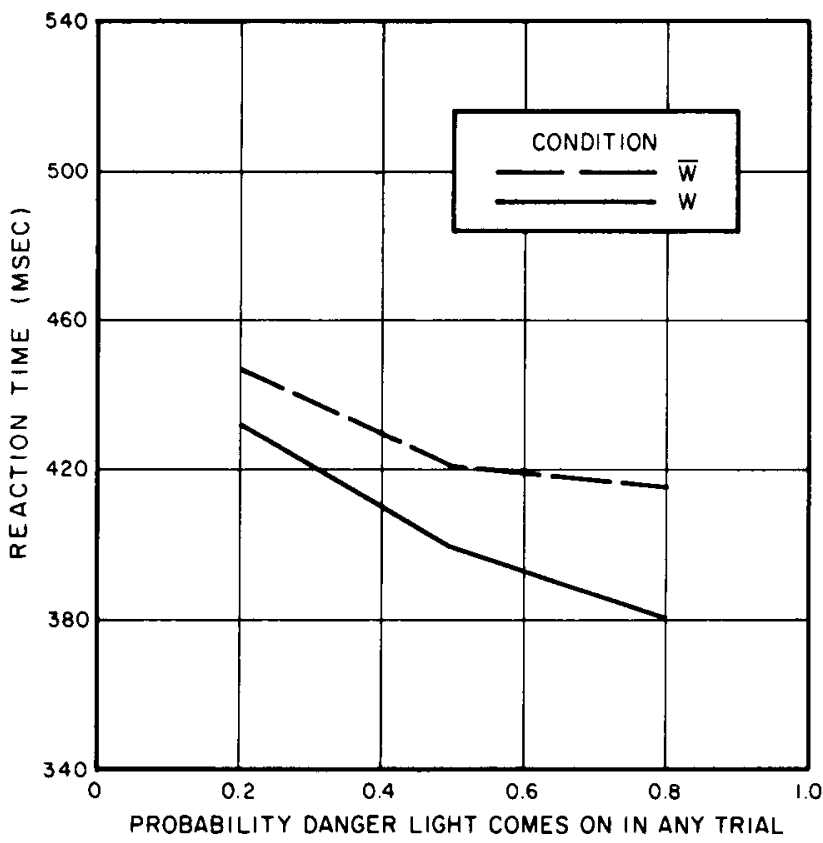

Fig. 1. Reaction time as a function of the probability that the danger light comes on in any trial (Experiment 1).

time, or terminated at the onset of the danger light; and (4) the presence or absence of a secondary pedal that the $O$ was required to depress until the warning light occurred.

Whenever an $\mathrm{O}$ made an erroneous response, the trial was immediately terminated, and the type of error was recorded. Errors were of three types: (1) responses prior to the warning light onset, (2) responses after the warning light onset, but prior to the danger-light onset, and (3) responses after the warning-light offet when the danger light did not, in fact, come on. (A 1-sec waiting period was programmed to detect this last type of error.)

The probability that the warning light would occur on any trial was varied between 0 and 1 ; the probability that the danger light would occur was varied between 0.2 and 1.0 . The time between the onset of the warning light and that of the danger light (when both occurred) varied with equal likelihood over $0.0,0.125,0.25,0.5,1.0,2.0,4.0$, and $8.0 \mathrm{sec}$. This variable will be referred to as the W-D interval.

The conditions of the three experiments are summarized in Table 1. Those conditions where the warning light was not operative ( $\mathrm{a}, \mathrm{b}, \mathrm{c} ; 2 \mathrm{a}, \mathrm{b} ; 3 \mathrm{a})$ will be referred to as $\overline{\mathrm{W}}$ conditions. Those conditions where the warning light was operative (the remainder) will be designated as $W$ conditions. At the 0 interval in the $\mathrm{W}$ condition, the warning light was not, in fact, visible (was of 0 duration). The temporal structure of the $\bar{W}$ sessions was exactly like that of the $W$ sessions, except for the omission of the warning light in the former case.

\section{EXPERIMENT 1}

Four Os were used, two of whom were aware of the nature of the experiment. Each $O$ participated in six sessions consisting of 11 blocks of 64 trials each, with a rest period between each block. The first block for each session was a practice run, so that 640 trials per session were included in the data analysis. Each $\mathrm{O}$ was run first in the two conditions in which the probability of occurrence of the danger light was 0.5 , and the order of the 0.2 and 0.8 conditions was then counterbalanced across Os. The order of the $W$ and $\bar{W}$ conditions at each probability was also counterbalanced across Os.
Between depression of the response pedal (which turned off the danger light) and the onset of the next warning light, there was a variable-length interval. In the $\bar{W}$ sessions the range of intervals between successive occurrences of the warning light varied exponentially from 2 to $10 \mathrm{sec}$. In the $W$ conditions, the minimum time between occurrences of the danger light was $2 \mathrm{sec}$, but the maximum time was indefinite and varied with the probability of occurrence of the danger light.

\section{Results}

Based upon the average of individual O's medians, Fig. 1 shows that RT is a decreasing function of the probability of occurrence of the danger light in both the $W$ and $\bar{W}$ conditions. (Data for the $W$ condition do not include the 0 interval: inclusion of that interval would increase RT by about $10 \mathrm{msec}$ at each point.) The effect of the conditional probability with which the warning light preceded the danger light would be expected to produce a steeper function in the $W$ condition. This effect is suggested by the figure and is representative of the performance of individual Os.

Figure 2 shows RT as a function of different W-D intervals (plotted logarithmically except for the 0 interval). The maximum improvement (decrease in RT) for all probabilities with use of the warning light is found at the shortest (non-zero) intervals. At the longest intervals, the usefulness of the warning light is small and disappears entirely in this range at the 0.2 probability. Figure 2 also shows a large increase in $\mathrm{RT}$ at the 0 interval in the $\mathrm{W}$ condition. Finally, there was an increase in erroneous responses from four in the $\bar{W}$ conditions to 33 in the $\mathrm{W}$ conditions.

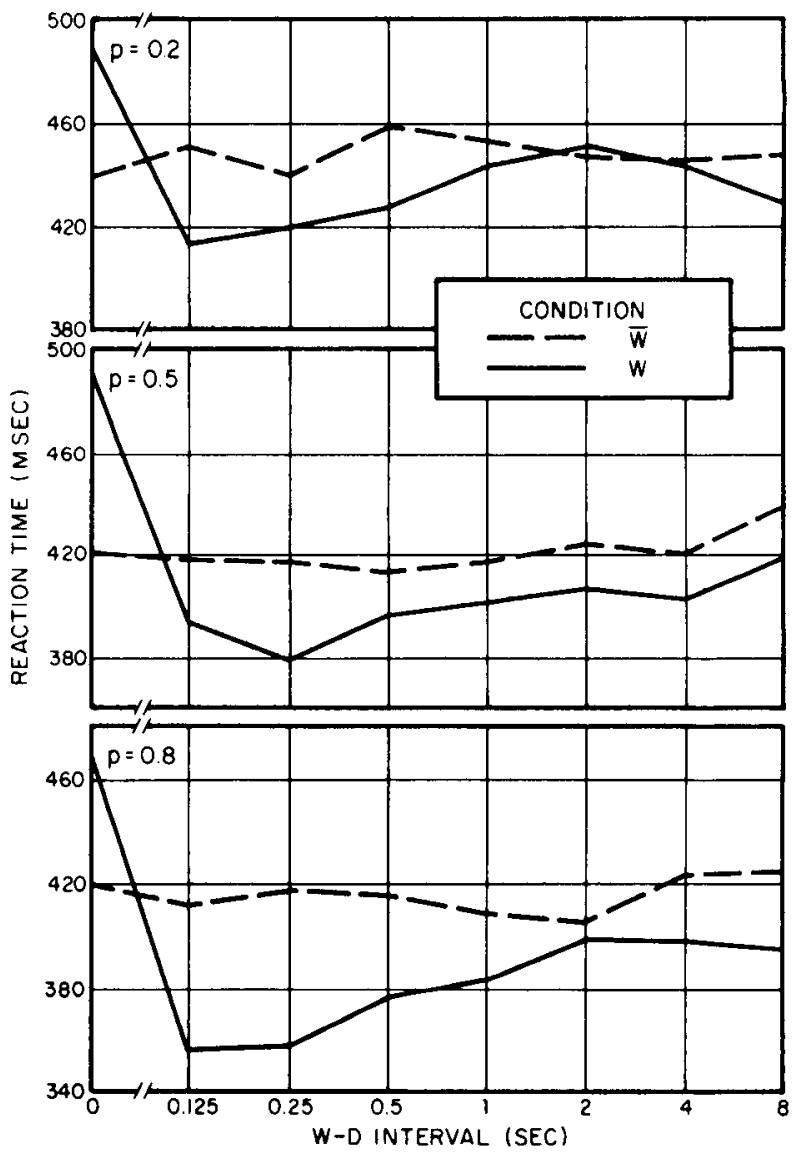

Fig. 2. Reaction time as a function of the W-D interval (Experiment 1). The individual graphs represent different probabilities of danger light occurrence. 


\section{Discussion}

The findings of Experiment I may be summarized as: (1) RT to the danger light tended to be slightly shorter when a warning light was used: (2) RT to the danger light varied inversely with the probability that the danger light would follow the warning light; (3) RT to the danger light tended to be shortest when the W-D interval was relatively brief, i.e., 125 to $250 \mathrm{msec}$; and (4) RT was unusually long if the warning light was expected but did not occur ( 0 interval, $W$ condition).

The first result supports the notion that a warning signal could be effective in reducing $\mathrm{RT}$ to a danger signal, even if the latter does not follow the fomer with certainty and the time between the two signals is not constant. The second indicates the advisability of implementing the warning signal so that it occurs only when the probability that it will be followed by the danger signal is high. In the driving context, for example, a warning triggered by full release of the accelerator would probably be more effective than one triggered merely by a decrease in accelerator pressure.

The apparent superiority of the $125-250 \mathrm{msec}$ intersignal interval may be contingent on the specifics of the experimental situation. It may be accounted for by the fact that very little "movement time" was included in the task, inasmuch as the $O$ was allowed to rest his foot on the pedal. This possibility was investigated in Experiment 2.

The fourth finding illustrates the effect of an O's expectation as a determinant of his RT, and underscores the importance of considering the anomalous case. It is generally the case that by adding "decision-aiding" features to a system, to improve operation under normal conditions, one creates the potential for poorer performance if the decision aid fails. The argument that such failures may be rare may be partially offset by the fact that the rarer the event, the less likely is the $O$ to be prepared for it. Clearly, there is a tradeoff involved.

\section{EXPERIMENT 2}

The second experiment was essentially an extension of the first. The task situation was identical with the following exceptions. First, a secondary pedal was mounted beside the response pedal, and the $O$ was instructed not to remove his foot from the secondary pedal until the warning light came on. This restriction made the task somewhat more realistic and allowed us to evaluate the effect of a warning signal on RTs when the response included significant movement time. An obvious interpretation of the secondary pedal in the driving context is as an "accelerator" pedal.

Second, to the $W$ and $\bar{W}$ conditions of Experiment 1 , a third condition was added. This third condition was similar to the $W$ condition except that the warning light was not turned off when the danger light came on, but overlapped it instead. This will be referred to as the WR (warning light remaining on) condition. The reason for including the WR condition was to investigate long RTs obtained with the 0 interval in Experiment 1 . In the WR condition, the warning light always occurred, even in the 0 interval case where it was coincident with the danger light.

Four college students served as paid Os. Each had a total of 11 runs under each condition, and the order in which they encountered the conditions was suitably counterbalanced. Only two probabilities of occurrence of the danger light, 0.2 and 0.8 , were used with each of the three conditions. In all other respects the procedure in Experiment 2 was identical to that of Experiment 1.

\section{Results}

The data for Experiment 2 were analyzed in the same way as those for Experiment 1. Figure 3 shows RT as a function of the frequency with which the danger light came on, just as in Fig. 1. (Again, the 0-interval data were excluded from the two

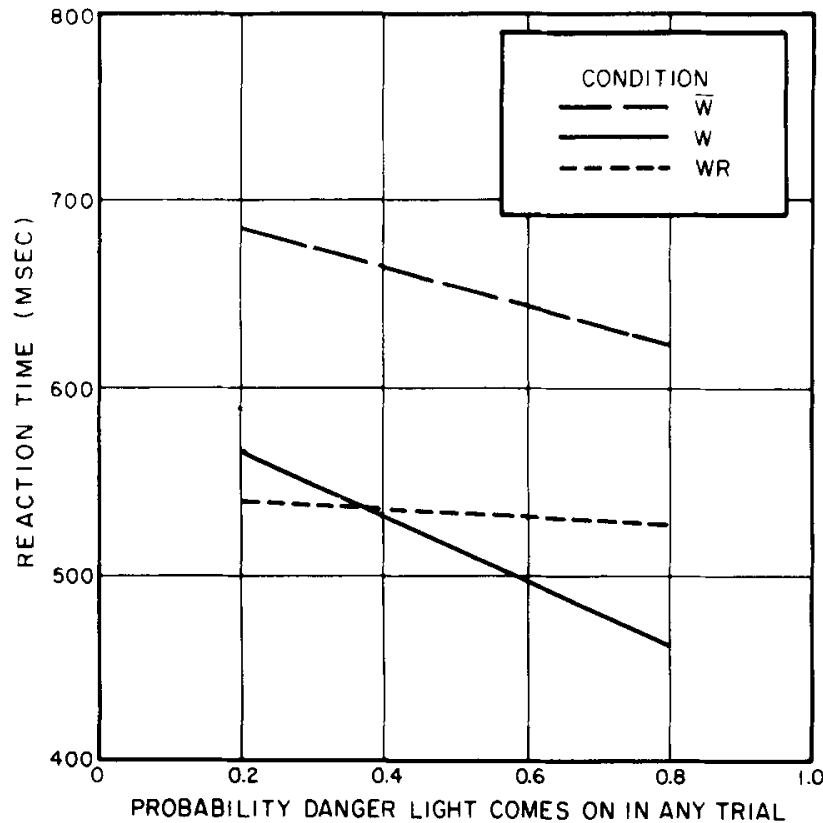

Fig. 3. Reaction time as a function of the probability that the danger light comes on in any trial (Experiment 2).

W conditions; inclusion of those data would have increased RT from 18 to $25 \mathrm{msec}$ in these cases.) The most striking difference between these two graphs is the much larger differences in absolute times between the $\bar{W}$ and the two $W$ conditions. The RTs obtained in the $\mathrm{W}$ conditions were 96-161 msec shorter than those obtained in the corresponding $\bar{W}$ conditions in this experiment, while in the previous experiment the largest difference was $35 \mathrm{msec}$. The heightened improvement can be attributed to the fact that when the warning light occurred, the $\mathrm{O}$ could anticipate the danger light by moving his foot over the response pedal, thus saving much of the movement time found in the $\bar{W}$ condition.

As in the previous experiment, the effect of decreasing the frequency of the danger light was to increase RT. There is no evidence in these data that the conditional probability of the danger light following the warning light affects RT. Nor is it clear why the WR condition should lead to faster responding than the $\mathrm{W}$ condition at 0.2 , but slower at 0.8 . While this is consistent over different W-D intervals, the effect is small compared to the differences between the $\overline{\mathrm{W}}$ condition and both $W$ conditions.

Figure 4 shows RT as a function of the W-D interval for 0.2 in the upper graph, and 0.8 in the lower. Except for the reversal mentioned above, the upper and lower curves have the same basic characteristics. The W and WR curves generally decrease in RT as the W-D interval increases, with a slight upturn in some cases at the longest intervals. This is in marked contrast to the corresponding curves for Experiment 1, where the shortest RTs were produced at the briefest W-D intervals. Finally, it is important to note that the WR condition produced shorter RTs at the 0 interval for each of the Os.

\section{Discussion}

The results of Experiment 1 showed that RT can be decreased even given a situation in which it is very short to begin with, i.e., in which movement time is minimal. The results of Experiment 2 indicate that the savings in time can be substantial in a situation where significant movement (from the secondary pedal to the response pedal) is necessary.

The results of this experiment suggest that to be maximally effective the W-D interval must be at least $1 \mathrm{sec}$ long. This, too, can be attributed to the fact that a limb movement is 


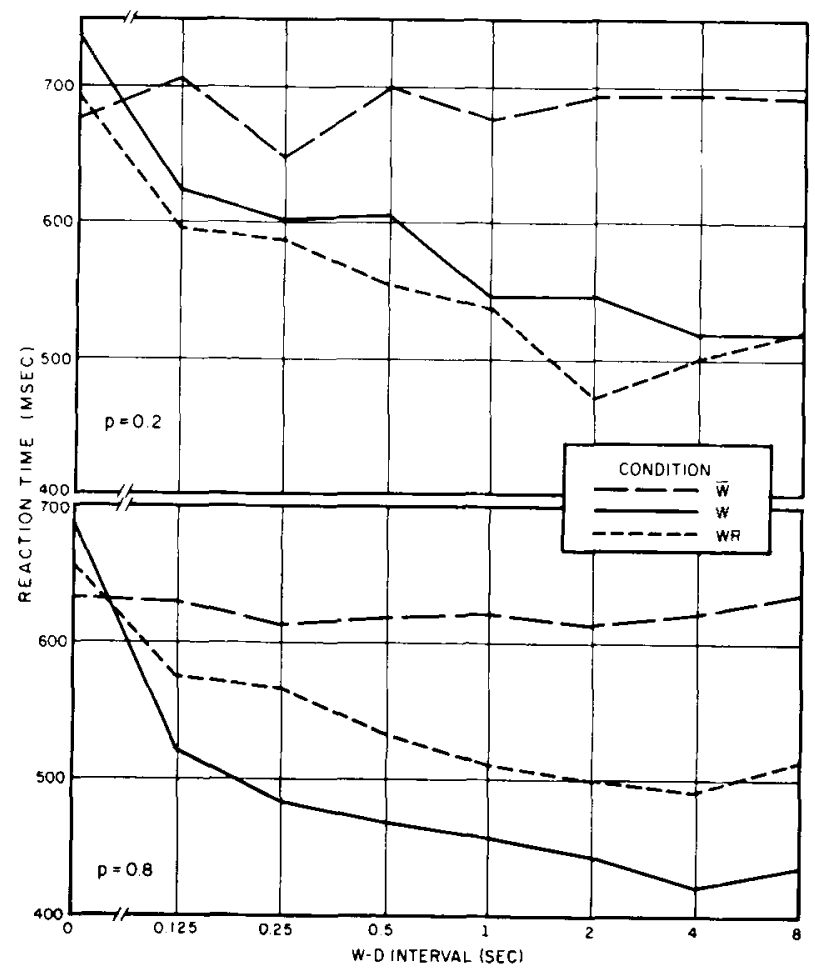

Fig. 4. Reaction time as a function of the W-D interval (Experiment 2). The individual graphs represent different probabilities of danger light occurrence.

involved in the response. The longer intervals are more helpful because they allow the $O$ to remove his foot from the secondary pedal and poise it over the response pedal before the danger light comes on. It should be noted, however, that even the shortest intervals (except the 0 interval) result in some decrease in RT.

The difference between the two $W$ conditions raises some interesting questions which need to be explored further. Until evidence to the contrary is available, however, it would appear that keeping the warning light on is helpful in the 0 -interval case, but not in any other. Again, however, the differences attributable to this variable are small relative to those attributable to the presence or absence of the warning light.

It may be noted in passing that the curves representing the $W$ and WR conditions are not unlike those frequently obtained in experiments on the "psychological refractory phase" (see also Fig. 6). For reviews of studies of this phenomenon, the reader is referred to Bertelson (1966) and Smith (1967).

\section{EXPERIMENT 3}

The results of Experiment 2 were equivocal with respect to the importance of having the danger light follow the warning light with high probability. To help resolve this question, it was decided to perform an experiment in which the frequency of the danger light is held constant, and that of the warning light is varied. This is the inverse of the paradigm used in the previous experiments and would help to distinguish the importance of contingent probabilities from that of the first-order probabilities.

In the $W$ and $W R$ conditions of the preceding experiments, the probability of the occurrence of the warning light was constant at 1.0 , while the probability of the occurrence of the danger light was varied. Letting $p(D)$ represent the probability of the occurrence of the danger light and $p(D \mid W)$, the probability of the danger light given that the warning light has occurred, we see that in Experiments .1 and 2, $p(D)=p(D \mid W)$.
In Experiment 3, p(D) was held constant while $p(W)$ was varied in such a way as to let $p(D / W)$ vary over $0.2,0.5$, and 0.8 . The average waiting time between successive occurrences of the danger light was $20 \mathrm{sec}$, which falls between the average inter-danger-light intervals for $p(D)=0.5$ and 0.2 of the previous experiments.

Because the frequency of occurrence of the danger light was held constant, only one $\bar{W}$ session was needed in this experiment, Each of the three probabilities of occurrence of the warning light was paired with both the $W$ and the WR conditions.

Two college students served as paid Os. Each ran under all seven conditions, the order in which they encountered the conditions being counterbalanced insofar as possible.

\section{Results}

The data for Experiment 3 were analyzed in the same way as were those of the previous experiments. However, the graphs for $\mathrm{O} 1$ and $\mathrm{O} 2$ are presented separately because of gross between-Os differences. It appears that these Os used rather different response strategies, as is discussed later.

In Fig. 5, RT for each $\mathrm{O}$ is plotted as a function of $\mathrm{p}(\mathrm{D} \mid \mathrm{W})$. As before, the 0 interval was not included in the average for either warning signal condition. The $\bar{W}$ RT shown was from the one $\bar{W}$ session, and although it is not properly associated with any probability on the abscissa, it is presented for comparison. RT clearly increases as $\mathrm{p}(\mathrm{D} \mid \mathrm{W})$ decreases below 0.5 , but the effect of $p(D \mid W)$ above 0.5 is small, and in opposite directions for the two Os.

Figure 6 contains the graph similar to those in Figs. 2 and 4, but only for the 0.5 probability. It was not considered necessary to show the corresponding 0.2 and 0.8 curves, since the effect of probability was much the same as in the first two studies.

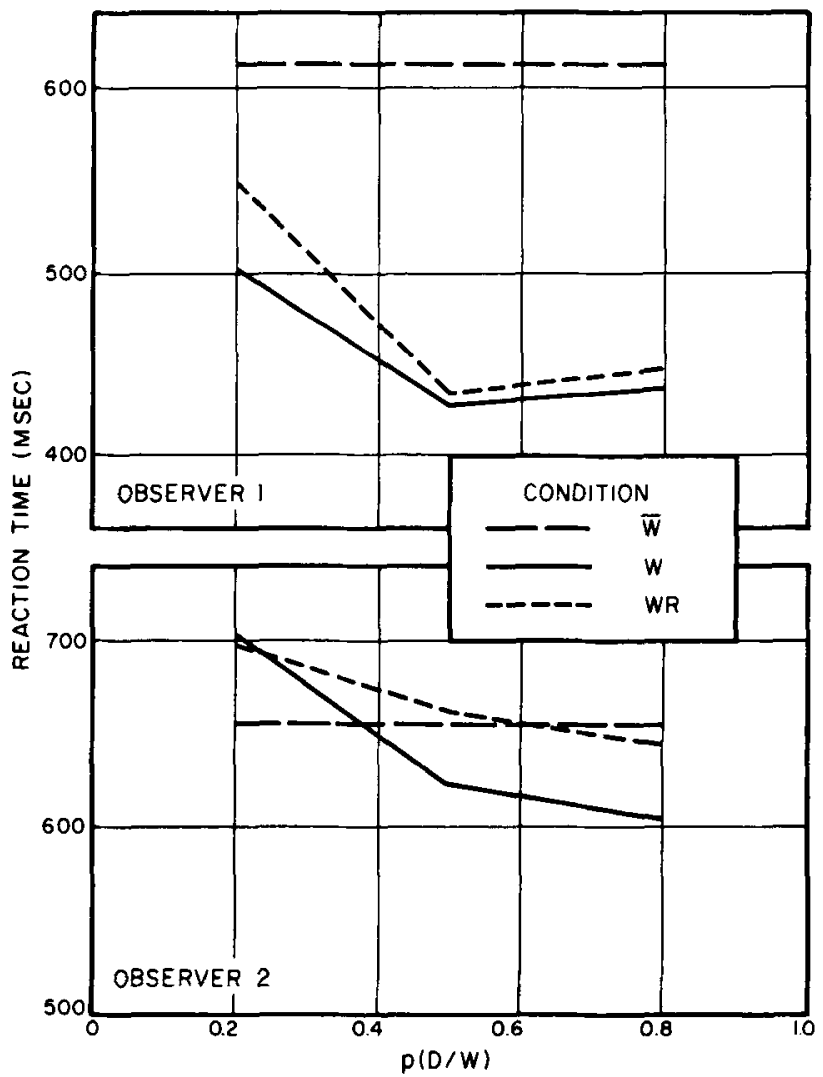

Fig. 5. Reaction time as a function of the probability that the danger light follows the warning light (Experiment 3 ). 


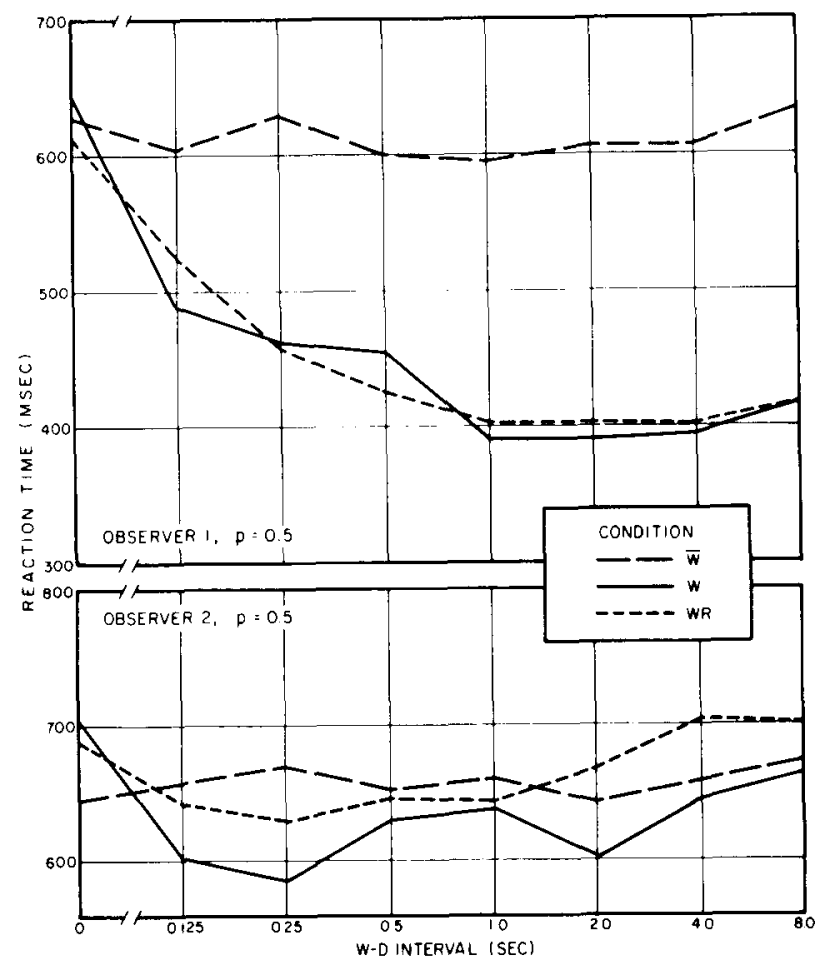

Fig. 6. Reaction time as a function of the W-D interval for a probability of 0.5 that the danger light follows the warning light (Experiment 3). The individual graphs are for different Os.

For O 1, the RT curve levels off by the 1-sec W-D interval, where the quickening in RT with the warning signal is about $200 \mathrm{msec}$. The data for $\mathrm{Ol}$ are very similar to the curves produced by three of the $\mathrm{Os}$ in Experiment 2. (O 3, in Experiment 2, produced results much like those of $\mathrm{O} 2$ in this experiment.) $\mathrm{O} 2$, on the other hand, achieved the greatest decreases in RT at the shortest intervals, 0.125 and $0.250 \mathrm{sec}$, just as did the $\mathrm{Os}$ in Experiment 1. The differences for $\mathrm{O} 2$

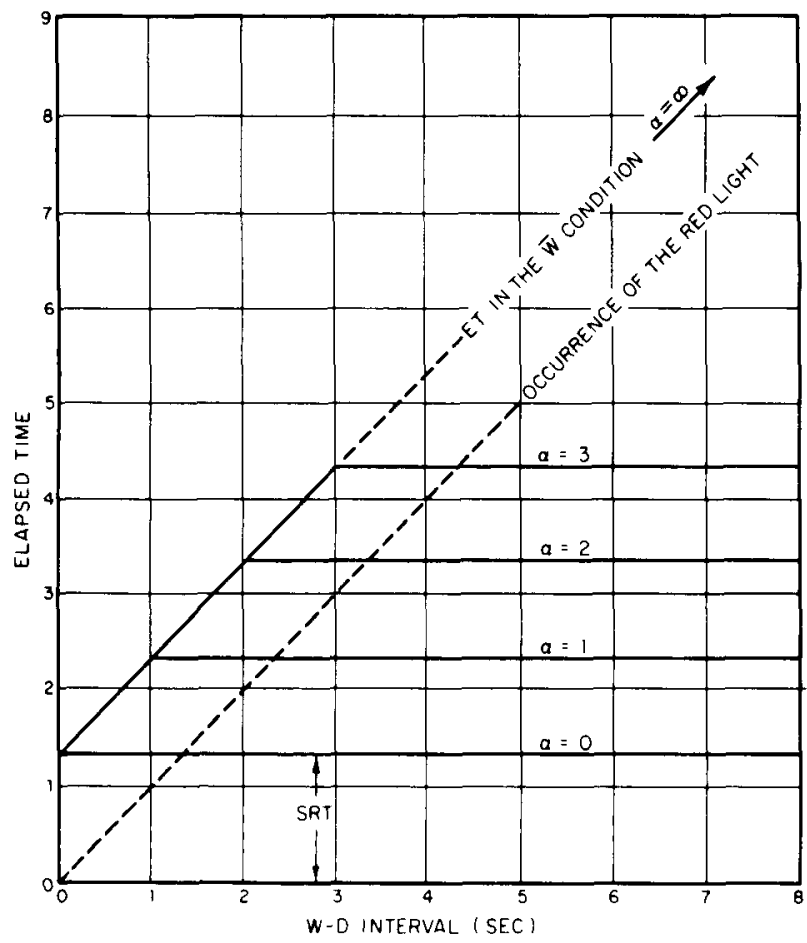

Fig. 7. Elapsed time predictions generated by $\alpha$-wait model as a function of the W-D interval. between the $\bar{W}$ condition and the original $W$ condition are of the same order of magnitude as those in Experiment 1, though the absolute times are longer, due to the movement time.

In 33 of the 42 comparisons between the $W$ and WR conditions for W-D intervals greater than 0 , RT was faster in the $W$ condition. At the 0 intervals, however, the WR condition invariably produced the faster RTs, as in Experiment 2.

\section{Discussion}

The large between-Os differences obtained in this experiment suggeșted that Os were utilizing different response strategies. To investigate this notion, a simple, two-parameter model was formulated and evaluated using data that had been recorded incidentally to the $\mathrm{RT}$ s to the danger light. These data available were the elapsed times after the onset of the warning light until the $\mathrm{O}$ removed his foot from the secondary pedal. The elapsed time is assumed to be composed of two additive components. The first component is a waiting time, $\alpha$, that is predetermined by the $O$ (but that can be interrupted by the onset of the danger light). The second component is the secondary pedal reaction time, SRT, to the warning (or where appropriate, danger) light. That is, SRT is the time required for the $\mathrm{O}$ to remove his foot from the secondary pedal if he attempts to do so as soon as the warning light comes on. Recall that the time interval from warning light onset until danger light onset is the W-D interval, and that occurrence of the danger light can interrupt the waiting time, $\alpha$. Then the elapsed time, ET, from warning light onset until release of the secondary pedal is given by:

$$
\mathrm{ET}=\mathrm{SRT}+\min [\alpha, \mathrm{W}-\mathrm{D}] .
$$

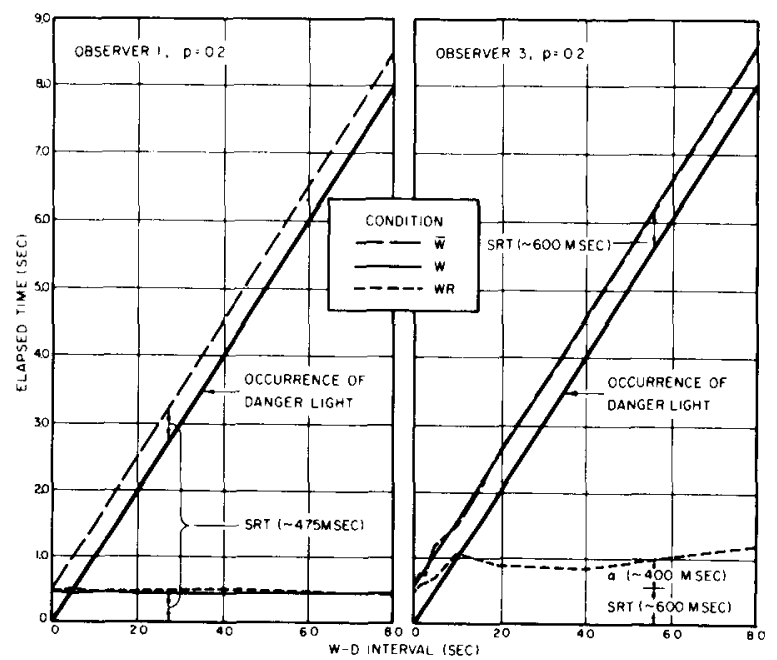

Fig. 8. Elapsed time for two Os as a function of the W-D interval (Experiment 2).

SRT can be separately estimated from the $\bar{W}$ condition, so if we plot ET as a function of the W-D interval, there remains only the free parameter, $\alpha$, to be estimated from the data. Figure 7 graphically illustrates the predictions of the model.

Figure 8 shows the elapsed time from the onset of the warning light to the removal of the foot from the secondary pedal (ET) as a function of the W-D interval for two Os in Experiment 2. O 1, shown on the left, used the strategy of removing her foot from the secondary pedal as soon as possible in both warning light conditions $(\alpha=0)$. This is apparent from the fact that her ET to the warning light in the $\mathrm{W}$ conditions is as fast as her SRT to the danger light in the $\bar{W}$ condition. Of the six Os in Experiments 2 and 3, only one consistently followed this strategy. 
Observer 3 was the least consistent of the six Os. In the W condition, he followed the strategy of leaving his foot on the secondary pedal until the red light came on. In the WR condition he used an $\alpha$-wait strategy on most trials, where $\alpha$ can be estimated at about $400 \mathrm{msec}$. His times in the WR condition, though, were highly variable over the range of $1 / 2$ to $2 \mathrm{sec}$, as was common with those Os who used an $\alpha$-wait strategy.

\section{CONCLUSIONS}

The results of these experiments support the notion that a warning signal could be an effective means of decreasing RT in operational situations in which the relationship between warning and danger signals can be defined only probabilistically. The results also substantiate the importance of both of the variables investigated (the probability that the warning signal would be followed by the danger signal, and the time between warning and danger signals).

Whether a warning signal would, in fact, decrease RTs can only be determined through careful testing in operational situations. The answer to this question will depend both on the specifics of the implementation scheme and on the extent to which operators use the time following warning-signal occurrence to prepare to make the response that will be required if and when the danger signal occurs.

The fact that one-third of the $O$ s in these experiments waited for the danger signal to come on before making any overt response to the warning signal emphasizes the importance of the latter consideration. We believe that the proposed alpha-wait model shows enough promise of being able to cope with response strategies to merit further investigation. It has the virtue of simplicity and accounts reasonably well for the data to which it was applied. It has only one free parameter, $\alpha$, inasmuch as SRT can be estimated in a separate experiment. The waiting time, $\alpha$, might be thought of as reflecting the risk-taking preferences of the operator.

\section{REFERENCES}

BERTELSON, P. Central intermittency twenty years later. Quarterly Journal of Experiment Psychology, 1966, 18, 153-163.

CROSLEY, J. K., \& ALLEN, M. J. Automobile rear signal lights: An evaluation of high placement, accelerator switching and driver responses. Bloomington, Indiana, Indiana University, Division of Optometry, draft, 1966.

MOORE, R. L., \& SMITH, H. P. R. Visibility from the driver's seat: The conspicuousness of vehicles, lights, and signats. In Proceedings of the Symposium on Ergonomics and Safety in Motor Car Design, London, September 1966.

ROCKWELL, T. H., \& TREITERER, J. Sensing and communication between vehicles. Columbus, Ohio, The Ohio State University, Systems Research Group, Transportation Engineering Center, Final Report EES 227-2, March 1966.

SMITH, M. Theories of the psychological refractory period. Psychological Bulletin, 1967, 67, 202-213.

\section{NOTES}

1. This research was sponsored jointly by the National Highway Safety Bureau, Department of Transportation, and the Human Performance Branch of the Ames Research Center, National Aeronautics and Space Administration. The authors wish to acknowledge the assistance of Miss Barbara Noel and Mr. Douglas Dodds.

2. Address: Bolt Beranek and Newman, Inc, 50 Moulton Street, Cambridge, Mass. 02138.

(Accepted for publication September 11, 1968.) 